STONE CENTER ON SOCIO-ECONOMIC INEQUALITY

WORKING PAPER SERIES

No. 25

Capitalist Systems and Income Inequality

Marco Ranaldi and Branko Milanovic

October 2020

REVISED

November 2020

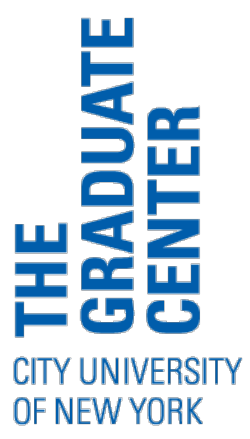




\title{
Capitalist Systems and Income Inequality ${ }^{1}$
}

\author{
Marco Ranaldi ${ }^{(1)}$ and Branko Milanović ${ }^{(1)(2)}$ \\ (1) Stone Center on Socio-Economic Inequality \\ The Graduate Center, CUNY \\ (2) International Inequalities Institute \\ London School of Economics
}

October 2020

\begin{abstract}
The paper investigates the relationship between capitalism systems and their levels of income and compositional inequality (how the composition of income between capital and labor varies along income distribution). Capitalism may be seen to range between Classical Capitalism, where the rich have only capital income, and the rest have only labor income, and Liberal Capitalism, where many people receive both capital and labor incomes. Using a new methodology and data from 47 countries over the past 25 years, we show that higher compositional inequality is associated with higher inter-personal inequality. Nordic countries are exceptional because they combine high compositional inequality with low inter-personal inequality. We speculate on the emergence of homoploutic societies where income composition may be the same for all, but Gini inequality nonetheless high, and introduce a new taxonomy of capitalist societies.
\end{abstract}

Keywords: inequality, capitalism, Gini, compositional inequality JEL classification: D31, P51 Number of words: About 8,300

\footnotetext{
${ }^{1}$ We thank Yaoqi Lin and Luis Angel Monroy-Gómez-Franco for the excellent research assistance. We also thank Mihail Arandarenko, Carlo D'Ippoliti, Mattia Fochesato, Christer Gunnarsson, Roberto Iacono, Ulysse Lojkine, Karl Ove Moene, Luis Angel Monroy-Gómez-Franco, Salvatore Morelli, Marc Morgan Milà, Elisa Palagi, Bilyana Petrova, John Roemer, David Soskice, David Weisstanner and Michael Zemmour for the very useful comments provided on a previous version of the manuscript. The usual disclaimer applies. Corresponding author: mranaldi@gc.cuny.edu.
} 


\section{Introduction}

The way capital and labor incomes are distributed across the population conveys precious information on systemic features of modern societies. Two particular distributions are especially relevant.

In the first distribution, one group of people earns only incomes from ownership (capital), and another group earns incomes only from work (labor). These two groups of people may not be overlapping in terms of total income. All members, or most members, of the former group (capital-owners) may be richer than any member of the latter group (workers). We label this society Classical Capitalism (Milanovic, 2017). It is a picture of a society implicit in the works of classical political economy, from Adam Smith to Ricardo and Marx. At the extreme, classical capitalism is a society where the rich earn only capital incomes, and the rest earn only labor incomes. In such a society, the type of income one receives determines also one's position in income distribution. The common assumption is that such societies tend to be unequal because capital owners are rich and capital income is fairly concentrated.

The second distribution describes, instead, a society in which individuals receive incomes both from capital and labor. We call this society Liberal Capitalism (Milanovic, 2019). In the extreme version of such a society, shares of income from capital and labor are equal for all members, and thus type of income and position in income distribution are orthogonal. ${ }^{2}$ In the sense of factoral income composition such a society is classless. A society of equal factoral composition needs not necessarily be a society of equal incomes (although it would be so if compositional and interpersonal inequality were positively correlated). It is theoretically possible that such a society has high income inequality.

In this paper we ask several questions: Can we identify societies of classical capitalism today and do they display higher income inequality than liberal

\footnotetext{
${ }^{2}$ In Milanovic (2017, pp. 245-8), it was called New Capitalism 2, to distinguish it from New Capitalism 1 where all individuals too receive both capital and labor incomes but capital share increases as one moves towards the higher parts of income distribution.
} 
capitalism? Are there other varieties of capitalism that we can describe using the same approach that distinguishes between compositional inequality and interpersonal income inequality? Are there "classless" societies of relatively equal compositional structure, and do they tend to have low or high inter-personal inequality?

This work empirically investigates the relationship between different varieties of capitalism, on the one hand, and their level of income inequality, on the other. Our definition of varieties of capitalist systems is different from those put forward by Hall and Soskice (2001) and Amable (2003), since it fully relies on distributional characteristics of the economies. While income inequality is commonly measured by standard statistics as the Gini coefficient, mapping social systems to numbers requires a different methodology. To proxy the extent to which a society can be more closely associated to classical capitalism, rather than to liberal capitalism, we adopt a novel statistic, the income-factor concentration (IFC) index defined in Ranaldi (2020). The IFC index measures the degree of income composition inequality, and can be used as a tool to analyze various capitalist economic systems.

We also use a much broader geographical coverage than is generally the case in the varieties of capitalism literature. We include 21 developed economies from Western Europe, North America and Oceania, 10 countries from Latin America, 11 from Eastern Europe, and 5 from Asia, including China and India. The total included population, calculated at the most recent year when a country is included in the database, is almost 4.4 billion.

IFC index is based on the following idea. If we decompose total income into two factors, such as capital and labor income, then income composition inequality is the extent to which the income composition is distributed unevenly across the income distribution. Compositional inequality is at the maximum when individuals at the top and at the bottom of the total income distribution earn two different types of income, and minimal when each individual has the same relative composition of the two types of income. Therefore, under a high level of compositional inequality a society can be seen as a case of classical capitalism, whereas under a low level 
of compositional inequality as a case of liberal capitalism. Furthermore, a high level of compositional inequality implies a strong relationship between the functional and personal distribution of income, whereas a low level implies a weak relationship between these two distributions. Hence, under classical capitalism, changes in the functional income distribution would readily translate into changes in the personal income distribution.

The paper is structured as follows. Section 2 presents the theoretical framework, in which we introduce a novel expression for the Gini coefficient and establish the relationship between compositional inequality (IFC) and interpersonal inequality (Gini). It also discusses the data we use. Section 3 gives the main results. Section 4 discusses a political economy interpretation of the main findings. Section 5 concludes.

\section{Methodology and Data}

\subsection{The Income-Factor Concentration Index}

As explained, the IFC index measures the level of compositional inequality, and it is constructed by means of specific concentration curves for income source. The concentration curve is a curve that cumulates the relative share of a given variable (such as capital income) across the population with individuals ranked according to another variable (such as total income). Three specific concentration curves are needed to construct the IFC index: the zero-, the actual-, and the maximum-concentration curve.

The zero-concentration curve is simply the Lorenz curve multiplied by the capital share. This curve reflects the condition of zero inequality in income composition. This condition is met when the individual capital share $\pi_{i}$ is, for all individuals, equal to the average capital share in the population $\pi$. Differently from the equality (or 45-degree) line used to construct the Gini coefficient, which is the same across distributions, the zero-concentration curve is distribution specific. Hence, two different distributions with different zero-concentration curves display, in turns, different benchmarks of zero inequality in income composition. 
The actual-concentration curve is, instead, the concentration curve for capital income with individuals being indexed by their total income rank. Also this curve is multiplied by the capital income share. When the area underlying the actual-concentration curve is high, the capital income is concentrated at the bottom of the income distribution. When this area is low, instead, the capital income is concentrated at the top of the total income distribution. Recall that this area is also the main ingredient used to calculate the pseudo-Gini coefficients (called also concentration coefficients), defined as 1 minus twice its value.

Finally, the maximum-concentration curve, which reflects the hypothetical condition of maximal inequality in income composition, is flat up to a certain income percentile $p$, and then mirrors the Lorenz curve. ${ }^{3}$ This curve describes a distribution in which the bottom $p \%$ of the total income distribution does not earn any capital income at all, whereas the top $(1-p) \%$ earns capital income only (this is the reason why, for this latter fraction of the population, the concentration curve for capital income mimics the Lorenz curve for total income). ${ }^{4}$

For illustrative purposes, we plot in Figure 1 the three concentration curves described above, together with the Lorenz curve for income for Egypt and Norway in 2012 and 2014, respectively. The Lorenz curve for income (blue line) for Egypt is, as expected, more convex than the Lorenz curve for Norway. This implies that the latter country is less unequal than the former in total income terms. The ending point of the three concentration curves corresponds to the capital share of income. This is approximately equal to 0.10 in both countries. ${ }^{5}$ For both countries the red line, which represents the actual-concentration curve, lies below the green line, which is the zero-concentration curve. For this reason, the maximum-

\footnotetext{
${ }^{3}$ For the details about the choice of $p$, see Ranaldi (2020).

${ }^{4}$ The maximum-concentration curve can also mirror the Lorenz curve up to a certain percentile $\mathrm{p}^{\prime}$, and then be flat. This curve describes a distribution in which the bottom $\mathrm{p}^{\prime} \%$ of the total income distribution does earn capital income only, whereas the top $\left(1-\mathrm{p}^{\prime}\right) \%$ earns labor income only. The choice of the maximumconcentration curve to adopt depends on whether the area underlying the actual-concentration curve is lower, or higher than that underlying the zero-concentration curve. When the area underlying the actual concentration curve is lower than that of the zero-concentration curve, then we should adopt the first maximum-concentration curve (in the text). In the contrary case, we should adopt the second maximumconcentration curve. We refer to the former curve as the preferred one, as it is more likely that capital incomes are concentrated at the top, rather than the bottom of the total income distribution.

${ }^{5}$ It is well known that the capital income share captured by the survey is much lower than that captured by the national accounts.
} 
concentration curve is flat up to a given percentile $p$, and then mimic the Lorenz curve for income. This means that the capital income is concentrated at the top of the total income distribution (and the labor income at the bottom) and, hence, that the level of income composition inequality is positive for both countries.

Figure 1. Lorenz curve and capital concentration curves for Egypt and Norway
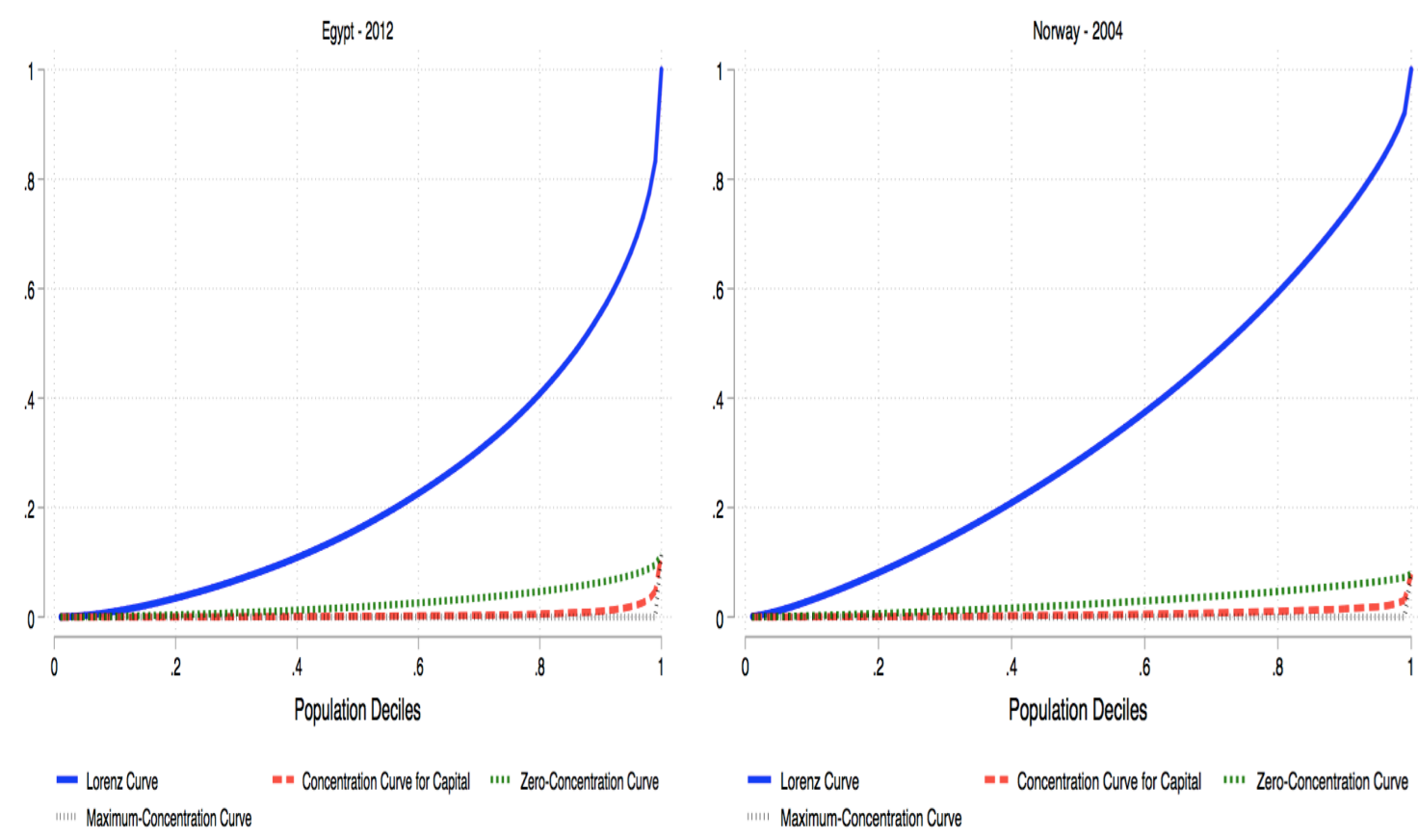

Let us now move to the construction of the IFC index. If, similarly to the definition of Gini or concentration coefficient, we denote by $A$ the area between the zero- and the actual-concentration curve, and by $B$ the area between the zero- and the maximum-concentration curve, we define the IFC index as follows:

$$
I F C=\frac{A}{B}
$$

IFC ranges between -1 and 1 . It equals 1 when the entire capital income is concentrated at the top and the labor income at the bottom of the total income distribution. It equals zero when all individuals have the same composition of capital and labor income (so income composition inequality is nil). Finally, it equals -1 when the capital income is concentrated at the bottom, and the labor income at 
the top of the total income distribution. Negative values of IFC are unlikely to be found in real world, probably both now and in history, since people having a high share of their income being derived from property were seldom poor. In our empirical example, the IFC index is equal to 0.84 for Egypt in 2012, and to 0.78 for Norway in 2004. For a representation of our two polar economic systems classical and liberal capitalism - in terms of distribution functions, see Appendix A.

\subsection{The Relationship between IFC and Gini}

Our objective is to study how related are compositional inequality (IFC) and inter-personal inequality (Gini). In this section, we present a framework to jointly study the two. To this end, we firstly introduce a novel formal expression for the Gini coefficient

$$
G=G_{\pi}^{\alpha} G_{w}^{\beta}
$$

where $G, G_{\pi}$ and $G_{w}$ are the Gini coefficients of total, capital and labor income, respectively (for the derivation see Appendix $\mathrm{B}$ ). The coefficients $\alpha$ and $\beta$ are the relative contributions of capital and labor to overall income inequality, and are

defined as follows: $\alpha=\frac{\pi \widetilde{G_{\pi}}}{G}$ and $\beta=\frac{w \widetilde{G_{w}}}{G}$, where $\pi$ and $\mathrm{w}$ are the capital and labor share, whilst $\widetilde{G_{\pi}}$ and $\widetilde{G_{w}}$ are the concentration coefficients (i.e. pseudo-Ginis) of capital and labor income, respectively. Notice that $\alpha=1-\beta$. As it will be shown later in this section, the $\alpha$ coefficient is of utmost importance for the joint study of income and compositional inequality. Equation 1 follows from the Euler's homogeneous function theorem, the same used to relate the Cobb-Douglas production function, $K^{a} L^{b}$, with the production identity, $Y=r K+w L$, under perfect competition, and from the decomposition of the Gini coefficient introduced by Lerman and Yitzhaki (1985). However, differently from the Cobb-Douglas production function, our expression for the Gini coefficient does not require any further assumption (such as that of perfect competition) to be derived. ${ }^{6}$ Our novel formulation of the Gini coefficient can, hence, be interpreted as a Cobb-Douglas

\footnotetext{
${ }^{6}$ See Appendix B for further details.
} 
inequality function.

Considering that the IFC index can be expressed as: ${ }^{7}$

$$
I=\frac{\pi w\left(\widetilde{\mathrm{G}_{\pi}}-\widetilde{\mathrm{G}_{\mathrm{w}}}\right)}{2 B}
$$

after further manipulations we obtain the following expression for the IFC index:

$$
I=\frac{G(\alpha \mathrm{w}-\beta \pi)}{2 B}
$$

The IFC-to-Gini ratio, central in our empirical assessment, can therefore be written as follows:

$$
\frac{I}{G}=\frac{(\alpha \mathrm{w}-\beta \pi)}{2 B}
$$

and if we further manipulate equation 4 we obtain:

$$
\frac{I}{G}=\frac{\alpha-\pi}{2 B}
$$

The dynamics of the IFC-to-Gini ratio can be, therefore, seen as a the result of two main forces (leave the denominator aside, for the moment), namely the contribution of capital income to overall income inequality, $\alpha$, and the capital share of income, $\pi .^{8}$

Several aspects of this relationship can be noticed. First, if the concentration coefficient $\widetilde{\mathrm{G}_{\pi}}$ was equal to the overall Gini coefficient $G$, then the

\footnotetext{
${ }^{7}$ This comes from the fact that the IFC index can also be expressed as follows: $I=\frac{\pi w\left(C_{w}-C_{\pi}\right)}{B}$, where $C_{w}$ and $C_{\pi}$ are the areas of the concentration curves for labor and capital income, respectively (see Ranaldi, 2020). Given that the pseudo-Gini coefficients for capital and labor income (here denoted by $\widetilde{G_{\pi}}$ and $\widetilde{G_{w}}$ ) equal 1 minus twice the value of the area of the corresponding concentration curve, the numerator of the IFC index can be re-arranged to obtain equation (2).

${ }^{8}$ Note that, as shown by Ranaldi (2019), the denominator of the IFC index, $B$, contributes very little in explaining the overall dynamics of IFC. IFC is mainly driven by movements of its numerator.
} 
IFC index would be zero, as $\alpha=\pi$. When the concentration coefficient of an income source is equal to the Gini it means that the two curves (concentration curve and Lorenz curve) are the same. Since the rankings underlying each curve are the same too, it means that income source is concentrated in exactly the same way as total income. This in turn implies zero compositional inequality, the result we obtain here.

Second, if we rewrite the equation above as follows:

$$
\frac{I}{G}=\frac{\frac{\pi \widetilde{G_{\pi}}}{G}-\pi}{2 B}=\frac{\pi\left(\frac{\widetilde{G_{\pi}}-G}{G}\right)}{2 B}=\frac{\pi \Delta G_{\pi}}{2 B}
$$

we observe that the numerator of the IFC-to-Gini ratio is the product of two elements, namely (i) the capital income share, and (ii) the relative gap between two measures of concentration (denoted $\Delta G_{\pi}$ ), namely, between the concentration coefficient of capital income and that of total income, both calculated across the total income distribution. If capital income share were constant across time, then the movements in the numerator of the IFC-Gini relationship would be driven solely by the gap $\Delta G_{\pi}$. If the concentration of capital increases faster than the concentration of total income, the $\frac{I}{G}$ ratio will go up.

\subsection{Data}

To measure the level of income inequality via the Gini coefficient, and that of income composition inequality via the IFC index for 47 countries from Europe, North America, Oceania, Asia, and Latin America in the last 25 years, we use data from the Luxembourg Income Study (LIS) Database, in total 302 countryrepresentative household surveys (see Data Annex). The Luxembourg Income Study Database collects and harmonizes microdata from more than 50 countries across the world, and provides information on household- and person-level labor income, capital income, self-employment income, pensions, other public social benefits, and private transfers, as well as taxes and contributions, demography, employment, and expenditures. 
The welfare concept adopted in our work is market income (income from capital and labor) plus pensions. Our benchmark definitions of capital and labor income are the following. Capital income is defined as the sum of interest incomes, dividends and rental incomes. Labor income is defined as the sum of wage income, self-employment income and pensions. The latter includes public non-contributory, public contributory, and private pensions. The rationale for including pensions is that they are viewed as deferred labor income (this is our Concept 1). However, in a further check, pensions are divided into public and private: the first are considered as deferred labor income, the second, most often received as a return on previously accumulated capital, are moved to capital income (this is our Concept 2). Self-employment income is throughout considered as pure labor income, and hence it is not split into a capital and labor components. This is done to avoid imposing an arbitrary split that may in turn considerably and unrealistically affect the overall picture. This is particularly the case in Latin American countries where self-employment income is quite and mostly received by the poor people and middle-income groups. ${ }^{9}$ Arbitrarily breaking that income into a labor and capital components (when the latter could be very small) might wrongly impart a relatively high share of capital income to the poor and the middle class.

The unit of analysis is the individual, and all income sources are equally split among household members.

To calculate the Gini coefficient in a given country and a given year, we use the averages of per capita total income for each percentile of the distribution. To calculate the capital and labor concentration coefficients, and then the IFC index, we use the averages of per capita labor and capital income for each percentile of the total income distribution. By creating these synthetic distributions, we however automatically remove any extreme value present within the top percentile (i.e. top $1 \%)$. Hence, our estimates have to be considered as lower bounds of, at least, our income inequality variable.

\footnotetext{
${ }^{9}$ If we take the examples of Brazil in 2016 and Mexico in 2018, the bottom 90\% of the income distribution has, in both countries, more than $65 \%$ of self-employment income, which by itself accounts for approximately the $20 \%$ of individuals' income.
} 


\section{Is compositional inequality associated with high-income inequality?}

\subsection{Compositional and inter-personal inequality}

As already mentioned, the first question we ask is whether compositional inequality, or in other words more class-based societies, tend to be more unequal, measured by the standard inter-personal inequality indices like the Gini coefficient. We have established the relationship analytically above but the question is whether it can be retrieved empirically.

We begin with rich countries of Western Europe, North America and Oceania and Concept 1 definitions of labor and capital incomes. Figure 2 presents the average values of Gini and IFC for 21 countries with a total of 166 observations spanning the period from 1995 to 2018.

Figure 2. Relationship between compositional and inter-personal inequality

(Western Europe, North America and Oceania)

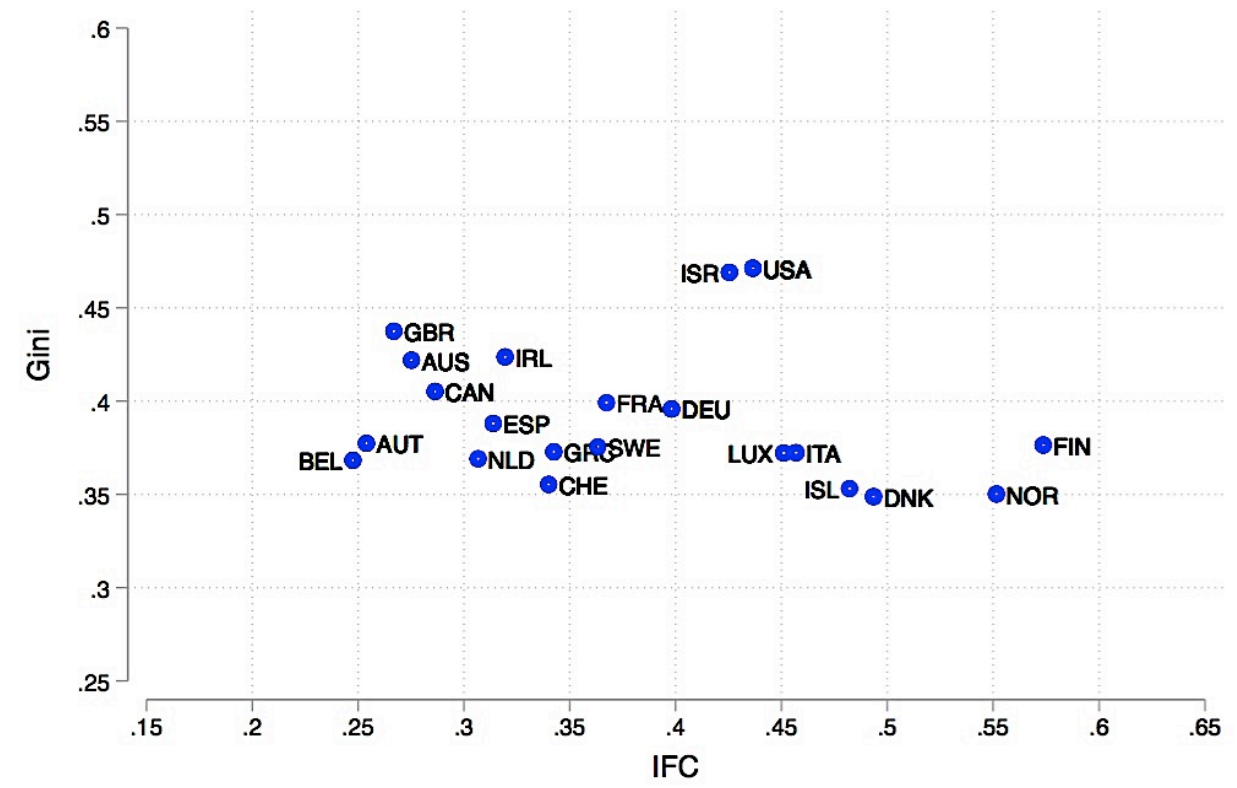

Note: Each dot is the unweighted average for a country.

Figure 2 shows that most rich countries are clustered in the relatively narrow range of IFC between 0.25 and 0.4 and Gini between 0.35 and 0.45 . But it also reveals several features that will be further discussed. First, it highlights the 
outlier positions of the United States and Israel: they both have an unusually high inequality (for rich countries) and higher IFC than the "core" countries in the cluster. Second, the graph reveals very high compositional inequality among Nordic countries (Finland, Norway, Denmark and Iceland), which is not accompanied by high income inequality. ${ }^{10}$ The graph also shows that Italy and Luxembourg (with practically the same values of IFC and Gini) represent the "bridge" between the core countries and the Nordics.

We next include all the countries (Figure 3). The dispersion is now, as expected, much greater but three clusters stand out. The first is the cluster of Latin American countries that traditionally have had high inter-personal inequality and which also exhibit high compositional inequality. They are located in the NE quadrant of the graph with both IFC and Gini values between 0.5 and 0.55 . They can be considered, on account of their high IFC, class-based societies associated with classical capitalism where, in our stylized presentation, we expect that people receive either capital or labor income (thus making IFC high) and that capitalowners be income-rich (thus making Gini high). Not all Latin American countries are however the same. Uruguay displays lower income inequality than one might have expected from its IFC; differently, Dominican Republic, Peru, and Colombia display higher.

\footnotetext{
${ }^{10}$ Sweden unfortunately has only three observations with the most recent being 2005 . After that year, Sweden no longer provides micro data to Luxembourg Income Study.
} 
Figure 3. Relationship between compositional and inter-personal inequality (all countries; Concept 1 division between labor and capital income)

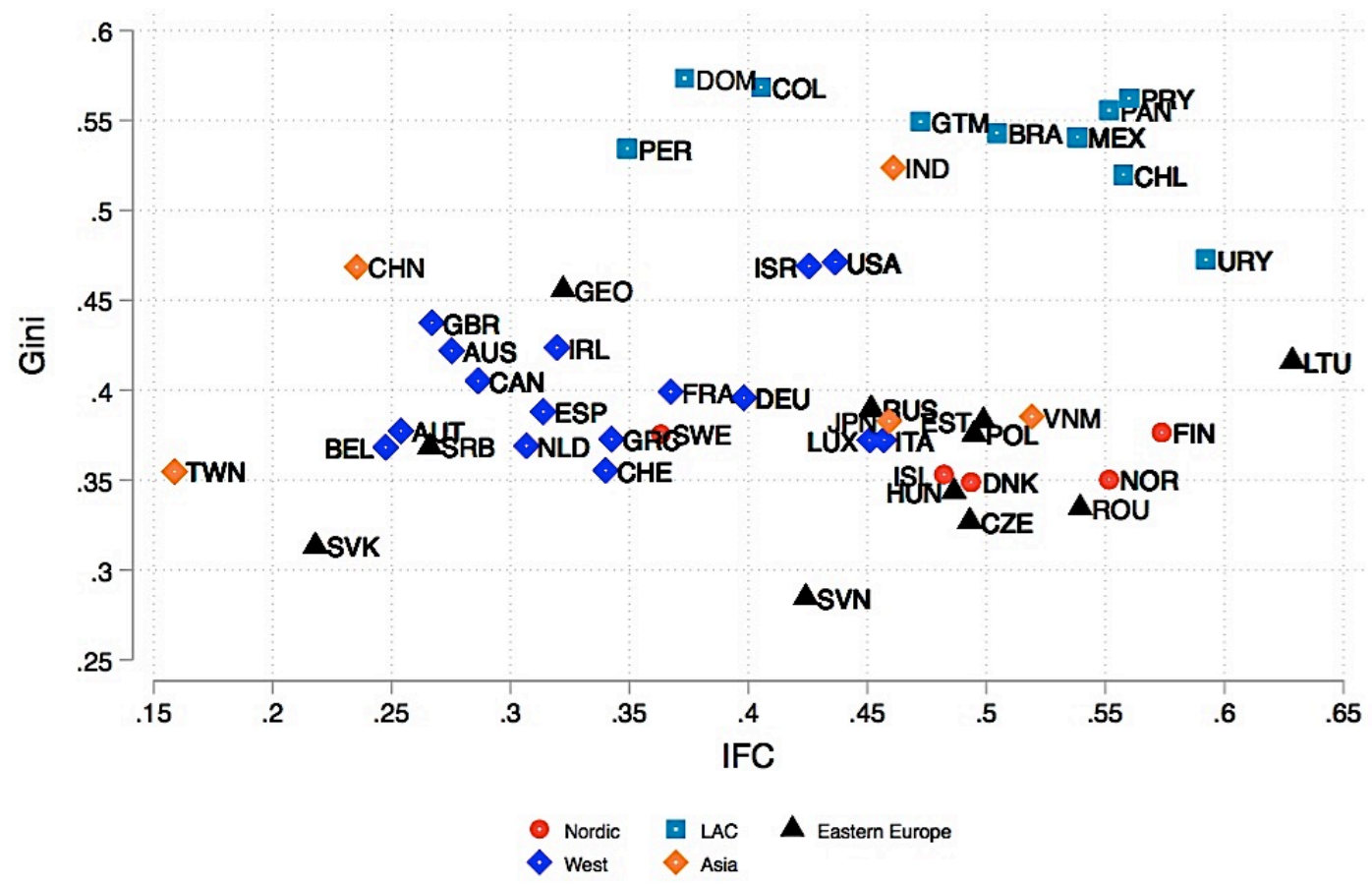

Note: The graph shows on the horizontal axis compositional inequality and on the vertical axis the standard measure of inter-personal income inequality (Gini coefficient). Nordic countries (Finland, Sweden, Norway and Denmark) are marked in red.

The central cluster of the advanced countries remains as before but they are now joined by Georgia and Serbia. In total 15 countries are within the range of IFC and Gini that we identified before (respectively, 0.25-0.4 and 0.3-0.45). They can be considered societies of liberal capitalism where class cleavages are less marked compared to classical capitalism.

North-Western quadrant is empty as there are no countries that combine low compositional and high inter-personal inequality. That implies that low classbased (that is, in our way of defining a class, "classless") societies are unlikely to be unequal. The reverse however does not hold.

\subsection{Nordic exceptionalism}

In the SE quadrant of the graph are Nordic countries (including Estonia among the Nordics too) joined by several Central European countries: Poland, 
Hungary, Czech Republic, and Romania. The position of this rather large cluster (ten countries) and especially of the Nordic countries among then, can best be appreciated if compared with the Latin American cluster. Nordics and LAC cover almost the same range in terms of compositional inequality (interestingly, Nordics are even more to the right than Latin American countries), but their income inequality outcomes are vastly different (Table 2). While Latin American countries have Ginis around 54, Nordic countries' average Gini is 36 (i.e. 18 Gini points lower). No Nordic country has a Gini above 38, and no Latin American country has a Gini below 47.

Table 2. IFC and Gini in Nordic and Latin American countries (Concept 1)

\begin{tabular}{|l|c|c|c|}
\hline & Mean IFC & Mean Gini & $\begin{array}{c}\text { Number of } \\
\text { observations }\end{array}$ \\
\hline Denmark & 0.49 & 0.35 & 7 \\
\hline Finland & 0.57 & 0.38 & 7 \\
\hline Norway & 0.55 & 0.35 & 6 \\
\hline Sweden & 0.36 & 0.38 & 3 \\
\hline Iceland & 0.48 & 0.35 & 3 \\
\hline Nordics & 0.51 & 0.36 & 26 \\
\hline & & & 5 \\
\hline Brazil & 0.50 & 0.54 & 10 \\
\hline Chile & 0.56 & 0.52 & 5 \\
\hline Colombia & 0.41 & 0.57 & 1 \\
\hline Dominican R. & 0.37 & 0.57 & 3 \\
\hline Guatemala & 0.47 & 0.55 & 11 \\
\hline Mexico & 0.54 & 0.54 & 3 \\
\hline Panama & 0.55 & 0.56 & 5 \\
\hline Peru & 0.35 & 0.53 & 6 \\
\hline Paraguay & 0.56 & 0.56 & 5 \\
\hline Uruguay & 0.59 & 0.47 & 54 \\
\hline Latin America & 0.51 & 0.54 & 6 . \\
\hline
\end{tabular}

Note: All pension income is treated as labor income. Regional averages are unweighted averages of all regional observations.

The Nordic group poses a very interesting question, even a puzzle: How have these countries combined an apparently strong class structure with moderate or even low income inequality? They are outliers to the rather strong relationship that we detect along the diagonal that runs from the classical capitalism to classless society and where IFC and Gini are positively correlated. In fact, the 
correlation coefficient between compositional and inter-personal inequality when the Nordic/Central European group is excluded is 0.28 and each point increase in IFC is associated with, on average, 0.15 point increase in Gini. But when we include the Nordic/Central European group, both statistics substantially weaken: the correlation between IFC and Gini becomes 0.25 , and each IFC point raises Gini by only 0.13 percentage points.

To solve this puzzle let us consider several elements. Note that Nordic countries display a substantially higher $\frac{I}{G}$ ratio than other advanced countries. From the relationship between $I$ and $G$ in (5), we know that high $\frac{I}{G}$ can be caused either by the high share of capital in total income $(\pi)$ or high contribution of capital to total inequality $(\alpha)$ which, in turn, is driven by high concentration coefficient of capital income. ${ }^{11}$ In fact, the right-end side of equation (5) can also be written as follows: $\pi\left(\widetilde{G_{\pi}}-1\right)$. Table 3 shows that Nordics' capital share is very similar to that of other advanced economies while the concentration coefficient of capital income is much greater. The gap in concentration coefficients is 7 points and is statistically significant. High capital concentration can be also observed if we consider the share of total income from capital received by the top decile of income-earners, which is unusually high in Nordic countries (see column 5 in Table 3).

Table 3. Differences between Nordic and other advanced economies (Concept 1)

\begin{tabular}{|l|c|c|c|c|c|c|}
\hline & & & & \multicolumn{2}{|c|}{$\begin{array}{c}\text { Concentration } \\
\text { coefficient }\end{array}$} & $\begin{array}{c}\text { Capital } \\
\text { income in } \\
\text { top decile's } \\
\text { total income } \\
\text { in \%) }\end{array}$ \\
\cline { 5 - 7 } & IFC & Gini & $\begin{array}{c}\text { Capital } \\
\text { share (in \%) }\end{array}$ & $\begin{array}{c}\text { Capital } \\
\text { income }\end{array}$ & $\begin{array}{c}\text { Labor } \\
\text { income }\end{array}$ & 11.7 \\
\hline $\begin{array}{l}\text { (1) Nordics } \\
\text { (2) Other } \\
\text { advanced } \\
\text { economies }\end{array}$ & 0.51 & 0.36 & 5.0 & 0.68 & 0.34 & 7.4 \\
\hline $\begin{array}{c}\text { The } \\
\text { difference } \\
(1)-(2)\end{array}$ & $+0.16^{* *}$ & $-0.05^{* *}$ & +0.7 & $+0.07^{* *}$ & $-0.06^{* *}$ & $+4.1^{* *}$ \\
\hline
\end{tabular}

\footnotetext{
${ }^{11}$ Note that $B$, in the denominator of (5), which represents the area between the zero-, and the maximum concentration curve for capital income, depends on the shape of the overall distribution (i.e. the Lorenz curve) and $\pi$.
} 
Note: In all cases, the values are unweighted country/year averages. The number of observations is 26 for Nordic countries and 125 for other advanced economies. Two asterisks indicate statistically significant difference between the means at less than 1 percent level. The capital shares are not statistically significantly different between the two groups.

Figure 4. Capital share and capital contribution to Gini in Nordic and other advanced economies (Concept 1)

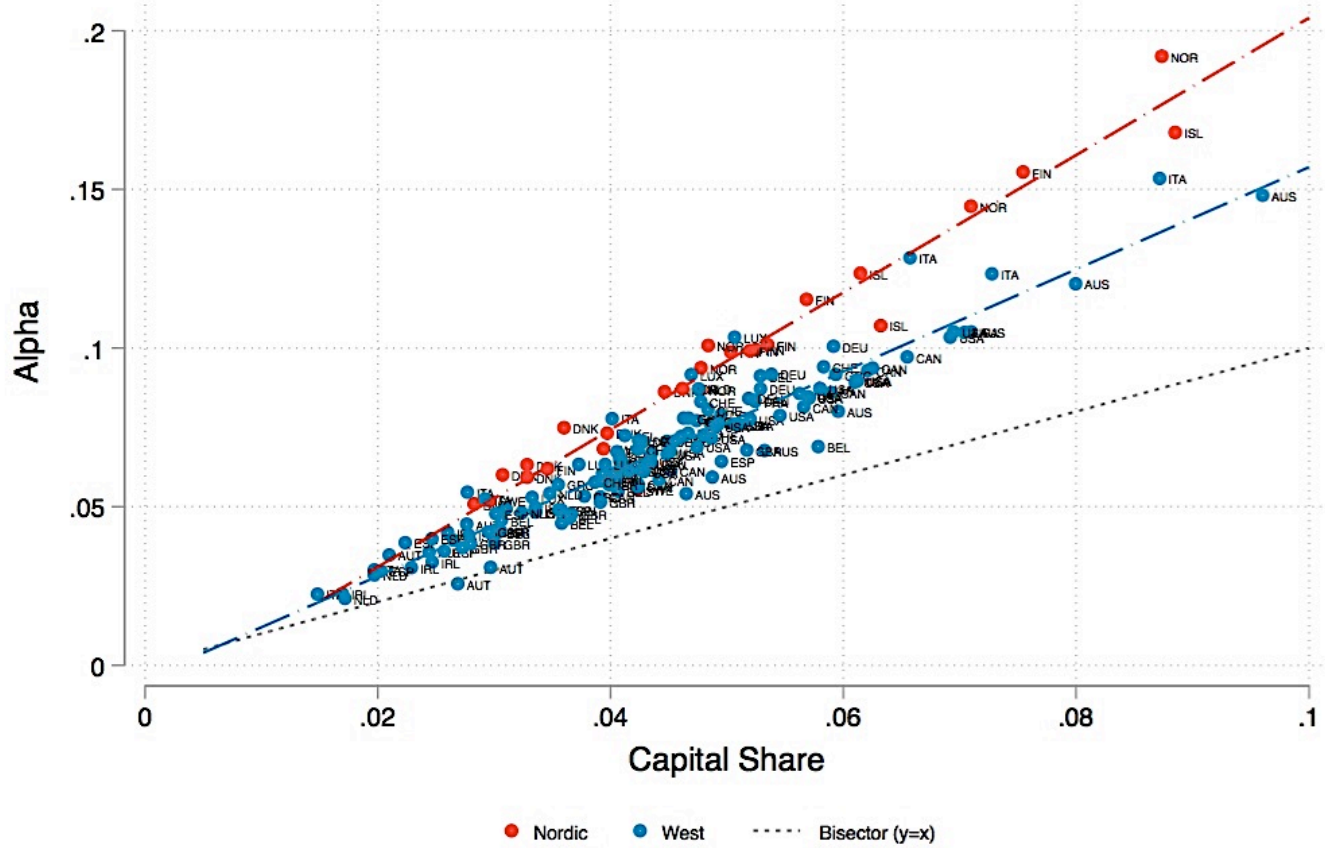

Note: The horizontal axis shows the share of capital in total income (e.g. $0.08=8 \%$ ) and the vertical axis the contribution of capital to total inequality $\alpha=\frac{\pi \widetilde{G_{\pi}}}{G}$. If capital income were distributed like overall income, the two shares would be the same (say, $8 \%$ of income would come from capital and explain $8 \%$ of total inequality). The fact that capital income tends to be more important among the rich explains that the capital's inequality contribution share is always greater than capital income share.

Much higher concentration of capital income among Nordic countries can also be observed if we compare capital share (on the horizontal axis in Figure 4) with capital contribution to total Gini (on the vertical axis). For any given capital share on the horizontal axis, contribution of capital income to Gini is higher among Nordic countries-implying that capital is more concentrated among the rich than elsewhere.

On the other hand, Nordic countries have a low concentration of labor incomes. Their average concentration coefficient of labor incomes is 0.34 versus 
0.4 for other advanced economies. (The difference is statistically significant). Low inequality of labor incomes, combined with a large labor share, pushes the overall inter-personal inequality down, and explains Nordics' low Gini.

In conclusion, Nordic countries display unusually high concentration of capital incomes and unusually low concentration of labor incomes. The former makes for high compositional inequality, the latter for low inter-personal inequality. This gives them the unique position where high IFC coexists with low Gini. In other words, they are class-based societies where the class-based component that normally leads to high Ginis is attenuated or "hidden" thanks to a very egalitarian distribution of labor earnings.

It is relevant to underline that our labor income variable includes both current wages and self-employment income, and pensions. (The full inclusion of pensions in labor income will be modified in the next section). A strong welfare state that has historically been associated with Nordic countries has ensured high pension replacement rates. ${ }^{12}$ This complements egalitarian access to education and egalitarian wage policies.

In the view of Karl Ove Moene (Moene and Wallerstein 2003; Moene 2016), the specificity of the Nordic model lies in the combination of wage compression, which implies relatively small wage skill differentials, with high returns to capital that are "socially acceptable" because of the implicit assumption that they are to be reinvested. This specificity of the Nordic model is reflected also in the fact that Nordic countries have high wealth inequality and low income inequality. The top decile's wealth share in Denmark, Sweden and Norway ranges between 65 and 76 percent which is significantly higher that the shares in Germany, the Netherlands, Spain or the UK which are all under 50 percent (Davies, Lluberas and Shorrocks, 2012). Fochesato and Bowles (2015) similarly argue that "Nordic exceptionalism" is not due to exceptional equality in wealth, but to high social mobility and low inequality of earnings. lacono and Palagi (2020) have documented the recent rise in compositional inequality in the Nordic countries, and claim that this was helped

\footnotetext{
12 In 2017, the average OECD gross pension replacement rate at mean earnings was $53 \%$; in Denmark it was $84 \%$, in Sweden and Finland 56-57\%, and in Norway 45\% (see OECD, 2017).
} 
by the emergence of Dual Income Tax (DIT) reforms in the early 1990s, characterized by a flat tax on capital incomes (which is considerably lower than the tax rate on labor incomes). Additionally, both Sweden (in 2004) and Norway (in 2014) have abolished taxation of inheritance.

Going back historically, it was argued that the compromise between capital and labor reached in the 1930s was based exactly on these premises: intact rights to capitalist accumulation with centralized bargaining over wages which tended to produce a more equal wage distribution (Rojas 1991, Esping-Andersen 1990).

\subsection{Classless economies}

Societies of low compositional inequality and low inequality are located in the SW quadrant of the graph. Two countries are closest to it: Taiwan and Slovakia. In terms of compositional inequality, China is very similar to these two countries. However, its Gini is much higher. It is noticeable that societies with low compositional inequality also have low inter-personal inequality (except China) thus reinforcing our previous point regarding the strong correlation between the two.

The position of China is worth highlighting because it reveals China's difference from the formerly communist countries that have transitioned to capitalism as well as from India. Compared with the first group, China is very unequal (its Gini exceeds even that of Russia), but its compositional inequality is much lower. It thus comes relatively close to the (empty) NW quadrant of the graph where would be located societies with low compositional but high interpersonal inequality.

India, on the other hand, shares in both respects (IFC and Gini) strong similarities with Latin American countries. It has already been observed (Milanovic, 2020) that India, when its distribution is assessed by income rather than by consumption (as was habitually done), has a Gini about equal to those we find in 
Latin America. ${ }^{13}$ What the analysis here reveals is that its compositional inequality is likewise very similar to that of Latin America. Thus in terms of compositional and inter-personal inequality India appears very "Latin American".

China's position allows us also to return to a point made in the introduction. Societies of compositional equality can still be income-unequal. We can imagine that developed societies may evolve in a direction where an upper class is created that is rich both in terms of labor and capital incomes. Individuals may either inherit significant wealth and get high levels of education and thus labor income, or alternatively may use their high labor incomes to save, and along the years, become rich capitalists while still working. This phenomenon was noticed by Milanovic (2019) and dubbed "homoploutia". It shows that conceptually, we cannot exclude the existence of developed capitalist societies with low compositional and high inter-personal inequality. ${ }^{14}$

\subsection{Nomenclature of capitalisms}

In Table 4 we propose a nomenclature of capitalisms based on the interplay between compositional and inter-personal inequality. The empirical results allow us to fill in the cells with the actually observed examples. Classical and liberal capitalisms take the central positions. Latin American countries show features associated with classical capitalism while Continental Europe, Canada and Australia can be considered liberal capitalist in virtue of their lower compositional and inter-personal inequality. The position of Nordic and Central European countries departs from that strong association between compositional and interpersonal inequality: they are class-based societies with low income inequality. The position of Nordic countries enables us to define more precisely, by analogy, the position of their antipode, homoploutic societies that have low compositional but high income inequality. We do not find actual societies that fit that description although China seems the closest. It could be also argued that high homoploutia

\footnotetext{
${ }^{13}$ According to the estimates of the World Inequality Lab (WIL), the Indian top $10 \%$ income share was equal to $56 \%$ in 2015, which is similar to the values for Brazil and Chile during the same year (both 55\%).

${ }^{14}$ In Milanovic (2019), homoploutia was defined with the reference to the top income groups whose members are rich in terms of both labor and capital income and hence have relatively similar shares of both. In this paper, we refer more broadly to homoploutic societies as those with similar shares of capital and labor throughout income distribution but with high inter-personal inequality.
} 
at the top of US income distribution where capital-rich households are increasingly also labor-income rich (Milanovic, 2019, Chapter 2) might drive the United States into the same direction.

Table 4. Nomenclature of capitalism

\begin{tabular}{|c|c|c|c|c|}
\hline & \multicolumn{4}{|c|}{ Compositional inequality } \\
\hline $\begin{array}{l}\text { Inter-personal } \\
\text { Inequality }\end{array}$ & Very low & Low & In-between & High \\
\hline Low & $\begin{array}{l}\text { Taiwan } \\
\text { Slovakia }\end{array}$ & $\begin{array}{c}\text { Liberal } \\
\text { capitalism } \\
\text { (Continental } \\
\text { European } \\
\text { countries, } \\
\text { Canada, } \\
\text { Australia) }\end{array}$ & $\begin{array}{c}\text { Russia } \\
\text { Japan } \\
\text { Italy }\end{array}$ & $\begin{array}{l}\text { Nordic and } \\
\text { Central } \\
\text { European } \\
\text { countries }\end{array}$ \\
\hline In-between & & China & $\begin{array}{c}\text { US } \\
\text { Israel }\end{array}$ & Uruguay \\
\hline High & [Homoploutia] & & $\begin{array}{c}\text { Dominican R } \\
\text { Peru } \\
\text { Colombia }\end{array}$ & $\begin{array}{c}\text { Classical } \\
\text { capitalism } \\
\text { (most Latin } \\
\text { American } \\
\text { countries, India) }\end{array}$ \\
\hline
\end{tabular}

The types of capitalism that we identified based on their observed inequality characteristics enrich the usual distinction between, on the one hand, classical capitalism with its heavily class-based structure and high inter-personal inequality, and liberal capitalism, with lower class distinction and lower Gini inequality. In this view, the evolutionary movement of capitalism takes place mostly along the diagonal that could be drawn in Table 4 from Latin American societies to Taiwan and Slovakia. It is indeed notable that empirically as one moves towards societies with lower compositional inequality, the level of inter-personal inequality goes down. However, that development is neither preordained nor without exceptions. We have seen that Nordic and some Central European societies do not fit into that scheme as they combine a strong class character with low overall income inequality. On the other hand, homoploutic societies to which China and the United States seem the closest may eliminate class structure but maintain high inequality. 


\subsection{Pensioner capitalism?}

So far we have treated all pension income as labor income. However, in an increasing number of countries, a part of pensions (occupational and private) is received as a return on forced or voluntary saving made during the working life. At the time of pension receipt, such income clearly represents a return on a financial asset and ought to be treated as capital income. In concept 2 therefore we split pensions into two components: capital component as just explained and all the rest of pension income which is, as before, assigned to labor income. Because of country differences both in the way the pension systems operate, and in the way that pensions are classified, it is likely that some private and occupational pensions are underreported, so that our split is biased toward assigning greater share of pensions to labor income. There is also the issue of guaranteed minimum pensions (social pensions) that are paid to people who are without resources in their old age and might not have acquired the right to "normal" pensions. These social pensions are, in some ways paid on account on citizenship, but we treat them as labor income. However that last type of pensions is small and unlikely to affect our results.

Figure 5 is drawn following the same idea as Figure 3 but with a different split between capital and labor incomes. The Ginis by definition remain the same, but IFCs change. Not much changes among the Latin American countries and our core cluster. However, Nordic countries "migrate" toward the core. They now appear much less of an outlier with compositional inequalities that do not depart much from those of France and Germany. It is notable that Denmark, Norway and Sweden are now all within the "central" cluster while Finland moves even further to the left. What this "migration" implies is that a relatively high share of occupational and private pensions in Nordic countries is received by the non-rich. This equalizes the shares of capital and labor income across income distribution. 
Figure 5. Relationship between compositional and inter-personal inequality (all countries; Concept 2 division between labor and capital income)

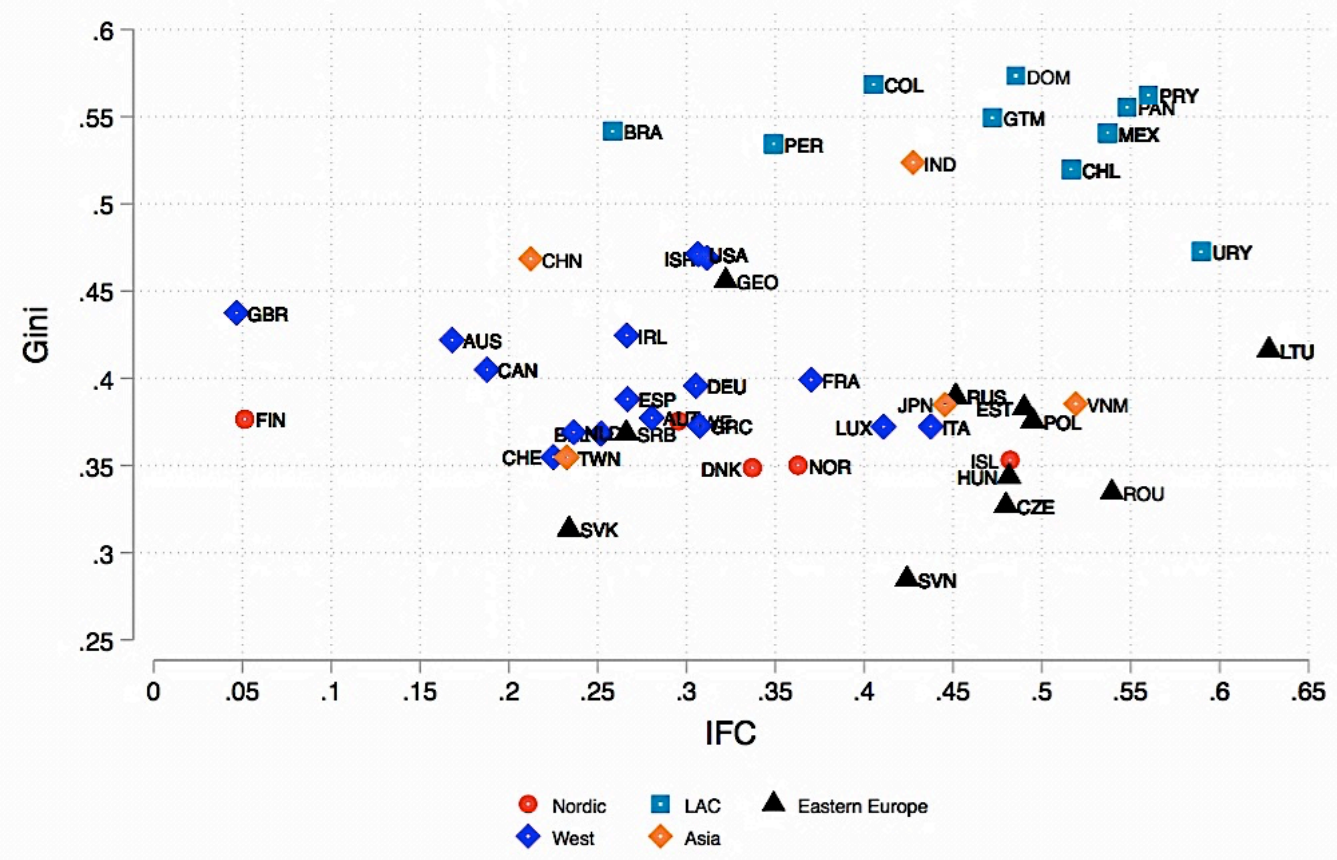

Note: The graph shows on the horizontal axis compositional inequality and on the vertical axis the standard measure of inter-personal income inequality (Gini coefficient). Nordic countries (Finland, Sweden, Norway and Denmark) highlighted in red.

It also presents an interesting model of "pensioners' capitalism". If the reduction in compositional inequality comes from private pensions that are received by people across income distribution, one can create, as Nordic countries seem to have done, a class-based society if assessed on its current work income, and much less so if assessed taking into account private pensions as well. As the share of older people is on the rise in many advanced countries and the use of private pensions becomes more popular, one can envisage a somewhat novel form of "classless" society where relatively equal shares of capital and labor across distribution are achieved through savings over active life and capital returns once in retirement. It is not the model that writers on either class or classless societies had in mind since their attention was focused on earnings during the active life, not on the role and position of the retirees.

What Figure 5 also highlights is that the SE quadrant is now populated mostly by Central European countries and only two Nordics, Estonia and Iceland. The reason is that private pensions are relatively rare in Central Europe, so the 
position of those countries does not change much between Concepts 1 and 2 . Countries that now seem the closest to a classless society are the United Kingdom and Finland. It is worth considering both. With Concept 1 division between labor and capital income, UK's IFC was 0.27 ; once we allow for occupational pensions, IFC goes down to 0.05 and makes UK the country with the lowest compositional inequality. Even more dramatically, Finland's IFC is reduced from 0.57 which was the level of compositional inequality exceeding Mexico's, to about 0.05 unmatched by any country except the UK. Private pensions have thus thoroughly transformed the class nature of these two, as well as of several other Nordic, countries.

The correlation between IFC and Gini remains broadly the same when as with Concept 1. For the whole sample the correlation is 0.2 and each point increase in IFC is associated with about 0.1 Gini point increase.

\section{Conclusion}

It has always been intuitive to expect a high level of inter-personal income inequality from class-based societies. In classical political economy's mind, a class-based society is characterized by a group of rich capital earners, which is opposed to a group of poor labor earners. Given the same nature of capitalist economies, whereby capital reproduces itself through new, profitable investment opportunities, the perpetuation of income inequality is an inevitable outcome. However theoretically reasonable this argument may be, none has ever tested it empirically. This is the objective of the present work, which addresses the following question: Does classical capitalism, or class-based society, display higher income inequality than liberal capitalism with much less stark division into property-owners and workers?

Using a new indicator that maps social systems empirically, the income-factor concentration (IFC) index, and data covering more 47 countries around the world in the last 25 years, we report two major findings on this relationship. First, more class-based societies are characterized by higher income inequality. Specifically, we find that a point increase in the IFC index, which measures the concentration of 
capital income at the top and labor income at the bottom of income distribution (that is, compositional inequality), is associated with between 0.1 and 0.13 percentage point increase in the Gini coefficient. Given that the Gini standard deviation in our sample is 0.07 , the average "effect" of compositional inequality on Gini is substantial.

Second, we observe countries clustering in three groups. Latin American countries have higher levels in both inequality dimensions (i.e. income and compositional inequality) than European and North American countries. The latter however have higher levels of income inequality but lower level of compositional inequality than Nordic and Central European countries.

The class-based nature of the Nordic countries, "hidden" by a low level of interpersonal inequality, is in line with the economic principles of the Scandinavian social compact. It combines wage compression, which implies relatively small wage skill differentials and generous pension replacement rates, with high returns to capital. The Nordic exceptionalism however gets attenuated or even disappears when a part of pensions that is received as a return on accumulated savings during the working life, is treated as capital income. Nordic countries become similar to the "core" advanced countries while some, like Finland, moreover show an exceptionally low compositional inequality.

There are no examples of countries that combine low compositional inequality and high inter-personal inequality (homoploutia). This reinforces our argument that once societies become "classless" (in the sense of having a low IFC), it is not likely that they would have high inter-personal inequality. Yet that possibility cannot be entirely excluded. We notice that China comes close to that position and one can speculate that the US might move in that direction too. The paper shows how the study of compositional and income inequality can be deployed to identify and explore the key features of contemporary capitalist societies. 


\section{References}

Amable, Bruno (2003), "The Diversity of Modern Capitalism”, Oxford University Press.

Atkinson, Anthony A. (1997), "Bringing income distribution in from the cold", The Economic Journal, vol. 107, March, pp. 297-321.

Autor, David and David Dorn (2010), "The growth of low-skill service jobs and the polarization of US labor market", American Economic Review, vol. 103, No. 5, pp. 1553-97.

Carluccio, Juan, Denis Fougère, and Erwan Gautier (2015) "Trade, wages, and collective bargaining: evidence from France", The Economic Journal, vol. 125, pp. 803837.

Davies, James, Rodrigo Lluberas and Anthony Shorrocks (2012), Credit Suisse Global Wealth Report 2012.

Ebenstein, Avraham, Ann Harrison and Margaret McMillan and Shannon Phillips (2014), "Estimating the Impact of Trade and Offshoring on American Workers Using the Current Population Surveys", Review of Economics and Statistics, October 2014, Vol. 96, No. 4: 581-595.

Esping-Andersen, Gøsta (1990), The Three Worlds of Welfare Capitalism, Cambridge, Polity Press.

Farber, Harry, Daniel Herbst, Ilyana Kuziemko, Suresh Naidu (2018), "Unions and Inequality Over the Twentieth Century: New Evidence from Survey Data", National Bureau of Economic Research Working Paper No. 24587, May.

Feenstra, Robert and Gordon H. Hanson (1999), "The impact of outsourcing and high-technology capital on wages: estimate for the United States, 1979-90", Quarterly Journal of Economics, vol. 114 (August). pp. 907-40.

Fochesato, Mattia and Samuel Bowles (2015), "Nordic exceptionalism? Social democratic egalitarianism in world-historic perspective", Journal of Public Economics, Vol. 127, July, pp. 30-44.

Goldin, Claudia and Lawrence F. Katz (2010), The Race between Education and Technology. Cambridge, MA: Belknap Press of Harvard University Press.

Hall, Peter A. and Soskice, David (2001), "Varieties of Capitalism: The Institutional Foundations of Comparative Advantage". Oxford University Press.

lacono, Roberto and Marco, Ranaldi (2020), "Poor Laborers and Rich Capitalists? On the Evolution of Income Composition Inequality in Italy 19892016". Stone Center Working Paper Series, No 13. 
lacono, Roberto and Palagi, Elisa (2020), "Still the Lands of Equality? On the Heterogeneity of Individual Factor Income Shares in the Nordics". LIS working papers series - No. 791.

Kuznets, Simon (1955), "Economic Growth and Income In equality." American Economic Review 45: 1-28.

Kuznets, Simon (1966), Modern Economic Growth. New Haven: Yale University Press.

Lydall, H. F. (1959), "The Long-Term Trend in the Size Distribution of Income", Journal of the Royal Statistical Society. Series A (General), Vol. 122, No. 1 (1959), pp. 1-36.

Milanovic, Branko (2005). "Can We Discern the Effect of Globalization on Income Distribution? Evidence from Household Budget Surveys", World Bank Economic Review, No. 1, pp. 21-44.

Milanovic, Branko (2017), Increasing Capital Income Share and its Effect on Personal Income Inequality, In After Piketty. The Agenda for Economics and Inequality. Edited by Heather Boushey, J. Bradford DeLong, Marshall Steinbaum. Ch. 10.

Milanovic, Branko (2019), Capitalism, Alone, Harvard University Press.

Moene, Karl Ove and Michael Wallerstein (2003), "Social democracy as a development strategy", Department of Economics, University of Oslo, No. $35 / 2003$.

Moene, Karl Ove (2016), "The Social Upper Class under Social Democracy." Nordic Economic Policy Review 2: 245-261.

OECD (2017), "Gross pension replacement rates", in Pensions at a Glance 2017: OECD and G20 Indicators,OECD Publishing, Paris

Piketty, Thomas (2014), Capital in the Twenty-First Century, trans. Arthur Goldhammer, Cambridge, MA: Harvard University Press.

Ranaldi, Marco (2019), "Income Composition Inequality: The Missing Dimension for Distributional Analysis", Economics and Finance. Université Panthéon-Sorbonne - Paris I.

Ranaldi, Marco (2020), Income Composition Inequality, Stone Center Working Paper Series, No 7.

Rojas, Mauricio (1991) The "Swedish model" in historical perspective, Scandinavian Economic History Review, 39:2, 64-74. 


\section{Appendix A}

In this section we represent our two polar economic systems - Classical and Liberal Capitalism - in terms of distribution functions.

Consider the following two random variables $\mathrm{X}$ and $\mathrm{Y}$ for the individual capital share of income (i.e. $\frac{\Pi_{i}}{Y_{i}}$ ) and total income, respectively. We know that $\mathrm{E}(\mathrm{X})=\pi$, where $\pi$ is the population capital share of income.

Classical capitalism $(c c)$ is described by the following probability functions of $\mathrm{X}$ and $\mathrm{Y}$ :

$$
\begin{gathered}
P^{c c}(X=x)= \begin{cases}p, & \text { if } \pi_{i}=0 \\
1-p, & \text { if } \pi_{i}=1\end{cases} \\
f_{Y}^{c c}= \begin{cases}f_{Y_{1}}^{c c}, & \text { if } \pi_{i}=0 \\
f_{Y_{2},}^{c c} & \text { if } \pi_{i}=1\end{cases}
\end{gathered}
$$

with $Y_{1} \in\left[y_{\min } ; y_{p}\right]$ and $Y_{2} \in\left[y_{p} ; y_{\max }\right]$, where $y_{\min }$ and $y_{\max }$ are the minimum and maximum income in the population, respectively. No further constraints on the functional forms of $\mathrm{f}_{\mathrm{Y}_{1}}^{\mathrm{cc}}$ and $\mathrm{f}_{\mathrm{Y}_{2}}^{\mathrm{cc}}$ are needed. $\mathrm{P}^{\mathrm{cc}}(\mathrm{X}=\mathrm{x})$ is, therefore, a Bernullian distribution with parameter $\mathrm{p}$. The latter parameter is defined as done for the maximum-concentration curve (i.e. the cumulative income of the bottom $\mathrm{p} \%$ of the total income distribution should be equal to the total labor income in the population). The different shapes of the $\mathrm{f}_{\mathrm{Y}_{1}}^{\mathrm{cc}}$ and $\mathrm{f}_{\mathrm{Y}_{2}}^{\mathrm{cc}}$ probability functions determine a given country's position in the strip $(1 ; \cdot)$ of the Gini-IFC diagram.

Liberal capitalism $(I C)$ is described by the following probability function of $\mathrm{X}:$

$$
\mathrm{Plc}^{\mathrm{lc}}(\mathrm{X}=\mathrm{x})= \begin{cases}1, & \text { if } \pi_{\mathrm{i}}=\pi \\ 0, & \text { if } \pi_{\mathrm{i}} \neq \pi\end{cases}
$$

No further constraints on the functional form of $\mathrm{f}_{\mathrm{Y}}^{\mathrm{lc}}$ are needed. $\mathrm{P}^{\mathrm{lc}}(\mathrm{X}=\mathrm{x})$ is a 
Dirac delta function. The different shapes of the $\mathrm{f}_{Y}^{\mathrm{lc}}$ probability function determine a given country's position in the strip $(0 ; \cdot)$ of the Gini-IFC diagram. Another way to describe Liberal Capitalism is the following. If $\mathrm{X} \sim 2 \pi \mathcal{U}[0,1]$ (recall that $\mathrm{E}(\mathrm{X})=\pi$ ), with $\mathcal{U}[0,1]$ be a uniform distribution, and $Y$ follows a given probability distribution $f_{Y}$, then the concentration curve for capital income (with individuals ranked according to total income) would tend, on average, towards the zero-concentration curve. This is due to the fact that the income distribution is, in this particular scenario, independent from the individual capital share of income distribution. 


\section{Appendix B}

From Lerman and Yitzhaki (1985) we know that the Gini coefficient can be decomposed in the following way:

$$
G=\pi G_{\pi} R_{\pi}+\mathrm{w} G_{w} R_{w}
$$

where $R_{\pi}=$ the ratio of two correlation coefficients $(\rho)$, between recipients' ranks according to total income $(y)$ and amount of capital income, and between recipients' ranks according to capital income and amount of capital income: $R_{\pi}=\frac{\operatorname{covar}(r(y), \pi)}{\operatorname{covar}(r(\pi), \pi)}=\frac{\rho(r(y), \pi)}{\rho(r(\pi), \pi)}$ and $R_{w}$ equivalently for labor income. By applying the Euler's homogeneous function theorem to the Gini decomposition equation, we obtain the following expression:

$$
G=G_{\pi}^{\alpha} G_{w}^{\beta}
$$

This function is homogeneous of degree 1 because when we multiply each argument by a scalar we get: $G\left(\gamma G_{\pi} ; \gamma G_{w}\right)=\gamma G\left(G_{\pi} ; G_{w}\right)$. In order to identify two formal expressions for $\alpha$ and $\beta$, we firstly calculate the partial derivatives of the overall Gini coefficient with respect to the Gini coefficients of capital and labor income. The partial derivative of the Gini coefficient with respect to the Gini coefficient of capital income yields:

$$
\frac{\partial G}{\partial G_{\pi}}=\alpha \frac{G}{G_{\pi}}
$$

Then, considering that $\frac{\partial G}{\partial G_{\pi}}=\pi R_{\pi}$ from Lerman and Yitzhaki (1985), we find the following:

$$
\alpha=\frac{\pi R_{\pi} G_{\pi}}{G} \in(0,1)
$$

The same procedure can be followed to derive $\beta$, which equals $\beta=\frac{w R_{w} G_{w}}{G}=1-$ $\alpha$. This can be also written as $\alpha=\frac{\pi \widetilde{G_{\pi}}}{G}$ and $\beta=\frac{w \widetilde{G_{w}}}{G}$ because $\widetilde{G_{\pi}}=R_{\pi} G_{\pi}$ and likewise $\widetilde{G_{w}}=R_{w} G_{w}$. 
Data Annex

The average values of Gini and IFC by country

\begin{tabular}{|c|c|c|c|}
\hline Country & Gini & $I F C$ & $\begin{array}{c}\text { Number of } \\
\text { observations } \\
\text { (household surveys) }\end{array}$ \\
\hline AUS & 0.422 & 0.275 & 7 \\
\hline AUT & 0.377 & 0.254 & 7 \\
\hline $\mathrm{BEL}$ & 0.368 & 0.248 & 8 \\
\hline BRA & 0.543 & 0.505 & 5 \\
\hline CAN & 0.405 & 0.286 & 12 \\
\hline $\mathrm{CHE}$ & 0.355 & 0.340 & 6 \\
\hline $\mathrm{CHL}$ & 0.520 & 0.558 & 10 \\
\hline $\mathrm{CHN}$ & 0.469 & 0.235 & 2 \\
\hline $\mathrm{COL}$ & 0.569 & 0.405 & 5 \\
\hline CZE & 0.327 & 0.493 & 7 \\
\hline DEU & 0.396 & 0.398 & 19 \\
\hline DNK & 0.349 & 0.494 & 7 \\
\hline DOM & 0.573 & 0.373 & 1 \\
\hline ESP & 0.388 & 0.314 & 7 \\
\hline EST & 0.383 & 0.499 & 5 \\
\hline FIN & 0.376 & 0.574 & 7 \\
\hline FRA & 0.399 & 0.367 & 3 \\
\hline GBR & 0.437 & 0.267 & 7 \\
\hline GEO & 0.456 & 0.322 & 3 \\
\hline GRC & 0.373 & 0.342 & 7 \\
\hline GTM & 0.549 & 0.472 & 3 \\
\hline HUN & 0.344 & 0.486 & 6 \\
\hline IND & 0.524 & 0.461 & 2 \\
\hline IRL & 0.424 & 0.319 & 6 \\
\hline ISL & 0.353 & 0.482 & 3 \\
\hline ISR & 0.469 & 0.425 & 8 \\
\hline ITA & 0.372 & 0.457 & 8 \\
\hline JPN & 0.383 & 0.459 & 3 \\
\hline LTU & 0.416 & 0.629 & 9 \\
\hline LUX & 0.372 & 0.451 & 6 \\
\hline MEX & 0.541 & 0.538 & 11 \\
\hline NLD & 0.369 & 0.307 & 5 \\
\hline NOR & 0.350 & 0.552 & 6 \\
\hline PAN & 0.556 & 0.552 & 3 \\
\hline PER & 0.534 & 0.349 & 5 \\
\hline $\mathrm{POL}$ & 0.376 & 0.495 & 7 \\
\hline PRY & 0.562 & 0.560 & 6 \\
\hline ROU & 0.335 & 0.539 & 2 \\
\hline RUS & 0.390 & 0.452 & 10 \\
\hline SRB & 0.369 & 0.266 & 4 \\
\hline SVK & 0.313 & 0.218 & 5 \\
\hline SVN & 0.285 & 0.424 & 7 \\
\hline SWE & 0.375 & 0.363 & 3 \\
\hline TWN & 0.355 & 0.159 & 8 \\
\hline URY & 0.473 & 0.592 & 5 \\
\hline USA & 0.471 & 0.437 & 24 \\
\hline VNM & 0.385 & 0.519 & 2 \\
\hline
\end{tabular}

Note: Ginis and IFC are unweighted country averages. 